\title{
Tweet me, Like me, Follow me: The Influence of Social Media and Technology on Children
}

Received: August 28, 2015; Accepted: November 13, 2015; Published: November 18, 2015

Today, if we ask parents what their children are doing right now, they might not know. Not that they have no idea about what activities their children are engaged in though. They might be aware that their children are surfing online, but have no idea about the specific content of those online activities.

According to a Kaiser study (Kaiser Family Foundation) [1], if children are awake and are not in school, they are most likely staring at a smart-phone, a computer, or watching television. This Kaiser study reveals just how addicted todays' children are to social media and technology. This study further suggests that media, from television to the social and electronic media such as cell phones, iPads, and Facebook, has become a dominant force in children's lives.

For years, the American Academy of Pediatrics (AAP) has also been concerned by evidence about the potential harmful effects of media messages and images. According to an AAP [2] policy statement, although television is still the predominant medium for young children and adolescents, new technologies are increasingly popular. Today, most 8 to 18 year-olds spend an average of more than seven hours to using social media across a typical day. It is not surprising that with technology allowing nearly 24-hour media access, the amount of time young people spend on social media has risen significantly (AAP; Kaiser Family Foundation) [1,2].

There is no doubt that the important and positive effects of media use should be recognized. For instance, social media offer us much in the way of connection and information. Internet, email, Twitter, video chats, and Facebook link us to people half way around the world, and also connects us more to our immediate communities. Media can also teach children empathy, racial and ethnic tolerance, and various skills. Further, TV shows like "Sesame Street", if used discretionally, can help children learn numbers and letters as well as prosocial skills.

But we all know they have their downside. For example, many researchers (e.g., Reilly et al.) [3] have found that television viewing has been found to play a significant role in the obesity story. Other problems associated with the use of technology and media include sleep deprivation, anxiety, depression, addiction, unhealthy exposure to radiation, as well as the long term potential harmful effects of media message and images on children's overall development. As a result, AAP [2] also maintains that the negative
Kaili Chen Zhang

Department of Education, Faculty of Social and Health Sciences, Unitec Institute of Technology, New Zealand

Corresponding author: Kaili Chen Zhang

\section{kailichenzhang@gmail.com}

Department of Education, Faculty of Social and Health Sciences, Unitec Institute of Technology, New Zealand.

Tel: 64 9-815 4321

media influences on children and teenagers should be recognized by schools, policymakers, product advertisers, and entertainment producers. Many educators would also agree that too much time spent on the Internet involved with social media or otherwise can result in a reduction in academic achievement, less time spent in sports, and less time spent with family. Dr. Sherry Turkle [4] from MIT, a specialist in technology and society, believes all of this virtual friendship is falling short of the real thing. In fact, she says, it's leaving us less human. After spending years researching the ways technology changes people, Turkle [4] concludes that by trying to replace the vulnerability, intimacy, conflict and messiness of actual friendships with electronic substitutes, we diminish part of what it means to be human.

However, increasingly, an overdose of and over-reliance on social media has contributed to the stress and the collective noise in our lives (e.g., Rowan and Turkle) [4,5]. In contrast, neuroscientists tell us that many of our most creative and productive moments come only when we step back from all the stimulation and let our minds be free. Turkle [4] also warns us of the need to cultivate a capacity for solitude, where we find ourselves so that we, in turn, can reach out to others to form genuine attachments. In other words, what many people call "loneliness" or "boredom" is good for our human brains. It is impossible for the constantlystimulated minds to be free and productive.

APA [2] states that infants aged 0-2 years should not have any exposure to technology, 3-5 years be restricted to one hour per day, and 6-18 years restricted to 2 hours per day. Children and youth use 4-5 times the recommended amount of technology, with serious and often life threatening consequences (Kaiser Family Foundation). AAP [2] also strongly encourage parents to establish a home use plan for all media.

But in reality what should parents and teachers do to cut 
children's screen time? First of all, teachers and parents must say no to themselves first. In order to detoxify the worldly clutter from our lives, we adults must first realize how much we have accumulated. I often challenge the student teachers I teach to embark on a social media detox. Students are asked to spend 24 hours, 3 days, or even a week totally "off-line." They are encouraged to spend deliberate time connecting with friends and family the old-fashioned way, that is, without the text-lingo, and many of the "online friend requests." This social media detox provides opportunity to focus more on important areas of life when social media is put aside.

So what is a parent to do next when her or his children start texting on the phone and chatting online? This is what a parent is to do: Set down some good rules. Many studies on children and media have suggested that interventions should aim at increasing parental knowledge about conditions of children's access to media. Strategies that improve parental consistency in monitoring children's media use may be of benefit as well. Therefore, parents should make rules limiting media consumption and access to technology, and make sure that their children will follow them. Before being allowed these privileges, a child must be old enough (e.g., over 15) and must agree to comply with boundaries parents and school set for him or her.

Indeed, adults' direct involvement in children's lives is a key element when designing intervention strategies to restrict access to smart phone, TV, tablets and electronic games. Technology and media are a poor substitute for personal contact and interactions. In today's online age which digital devices such smart phone and tablets have dramatically increased the accessibility and usage of technology, especially by very young children, it is critical that parents and educators provide personal guidance in limiting or monitoring age-appropriate screen time and programs. It is also essential for adults who are involved in children's lives provide opportunities that help children thoughtfully and intentionally develop authentic relationship skills, the ability to stay away from distraction, and to focus on what is truly important in life. 


\section{References}

1 http://kff.org/other/event/generation-m2-media-in-the-lives-of/.

2 American Academy of Pediatrics (2013) Children, adolescents, and the media. Pediatrics 132: 958-961.

3 Reilly J, Armstrong J, Dorosty A, Emmett P, Ness A, et al. (2005) Early life risk factors for obesity in childhood: Cohort study. British Medical Journal 330: 1357-1364.
4 Turkle S (2012) Alone together: Why we expect more from technology and less from each other. Jackson, TN: Basic Books.

5 Rowan C (2015) Ten reasons why handheld devices should be banned for children under the age of 12. http://www.huffingtonpost. com/cris-rowan/10-reasons-why-handheld-devices-should-bebanned_b_4899218.html. 